\title{
Role of Private School on Continuing Education in the Context of COVID-19 in Nepal
}

\author{
Dev Chandra Manandhar ${ }^{1}$, Siddhi Prasad Koirala (PhD) ${ }^{2}$ \\ ${ }^{1}$ Research Scholar, Mewar University, Rajasthan, India \\ ${ }^{2}$ Research Supervisor and Visiting Professor, Mewar University, Rajasthan, India \\ ${ }^{1}$ Email: manandhar0000@gmail.com²Email:siddhikoirala@gmail.com
}

Received: November 09, 2020; Revised \& Accepted: January 10, 2021; Published: February 18, 2021 (C) Copyright: Manandhar (2021).

\begin{abstract}
Government can apply learning continuity plan followed by private school during the lockdown period in the context of Covid-19 which appears as outbreak from Wuhan, China and spread rapidly all over the world. Since education is the systematic process of getting or receiving knowledge in the institutions, privatization of education is also being accepted by many countries and have brought the policy to emerge the education sector with the help of public and private schools. In the present context, when the Corona virus spread rapidly all over the world, WHO initiates to stay safe in quarantines and UNESCO suggest about closures of schools and universities. In this context, a study was conducted in 8 schools of every province of Nepal with Kathmandu valley. Schools were chosen randomly as well as mixed method was used to analyze the study. Chi-square, cross tabulation and correlation analysis was done to elaborate the data and SPSS vol-20 was used to interpret the data. In Nepal, private schools of urban area and some public schools are playing an effective role in continuing education through online learning constructing digital infrastructure. However, the majority of private schools are found less effective in online class due to geographic and socioeconomic conditions as well as they are facing electricity and internet problems to continue education in this pandemic era. So, government as well as private sector should prepare Temporary Learning Centre (TLC) and bring the Learning Continuity Plan (LCP) to urban and rural areas to continue education in the COVID -19 periods.
\end{abstract}

Keywords: Role, Private School, Continuity, Education, Covid-19

\section{INTRODUCTION}

Since an increasing number of cases of a novel Coronavirus (COVID-19) which was identified in Wuhan on December 2019, one of the large city having 11 million people in central China is now spreading all over the world( (Qun Li, 2020). So this situation leads the World Health Organization (WHO) to announce the outbreak for a Public Health Emergency of 
International Concern on 30 January 2020 and was recognized it as a pandemic on 11 March 2020. Later on, the number of people diagnosed with COVID-19 globally crossed above one million on April 2, 2020 as well as the case fatality rate across 204 countries (Chauhan). Also, the effects of COVID-19 appear in different areas globally, including education sector also. According to Murati (2016), school is such an organization that teaches significant life goals in the social context and aims to educate children with constructive values and philosophy which we are familiar and are the foundation of social ethics (Murati, 2016). A review by Jingjing (2015) explains that high-quality education will begin in the education process for educators for the educational purpose of promoting the educator's information, skills and other parts (Jingjing, 2015).

According to Verger (2016), the privatization of education is a worldwide observable fact and can also contribute to the positive development of education systems for different purpose and is being adopted by key education stakeholders. So, this is an important change with major implications that education systems are governed wide-reaching (Verger, Clara, \& Adrian, 2016).

Moreover, privatization of education in the 21 st century became as essential keeping in mind with the large population and their get in touch with for education. (Mandal \& Goswami, 2016). In so many under developing countries, the involvement of private-sector is spreading not due to the governments but to address new educational technologies. (Verger, Clara, \& Adrian, 2016). That's why there is gratitude of this sector which needs to unite in upcoming future where students from various sections can be supported through digital infrastructures (Crawford, et al., 2020).

As the COVID-19 pandemic spreads, many governments are trying to control the diseases by preventing gathering in public places and is likely to continue in some countries for a certain time until a vaccine or remedial measures will be identified and leaders of public and private education institutions are trying to conduct different methods for students to continue education rather to go schools. (Reimers, Schleicher, Saavedra, \& Tuominen, 2020) Globally, different countries have introduced various solutions during the case of COVID -19 pandemic to continue the education process such as online channels, course of action, resources, video lectures, TV broadcasts, online libraries which were introduced in at least 96 countries (Giorgi, 2020).

The main objective of this study is to find out the roles of private school for continuing education in the context of Covid-19 in Nepal. Similarly, the researcher has set up the null hypothesis to test the effectiveness of online class and is herewith: Null Hypothesis H0: There is no significant effect of online class continued by the private sector. 


\subsection{CONCEPTUAL FRAMEWORK}

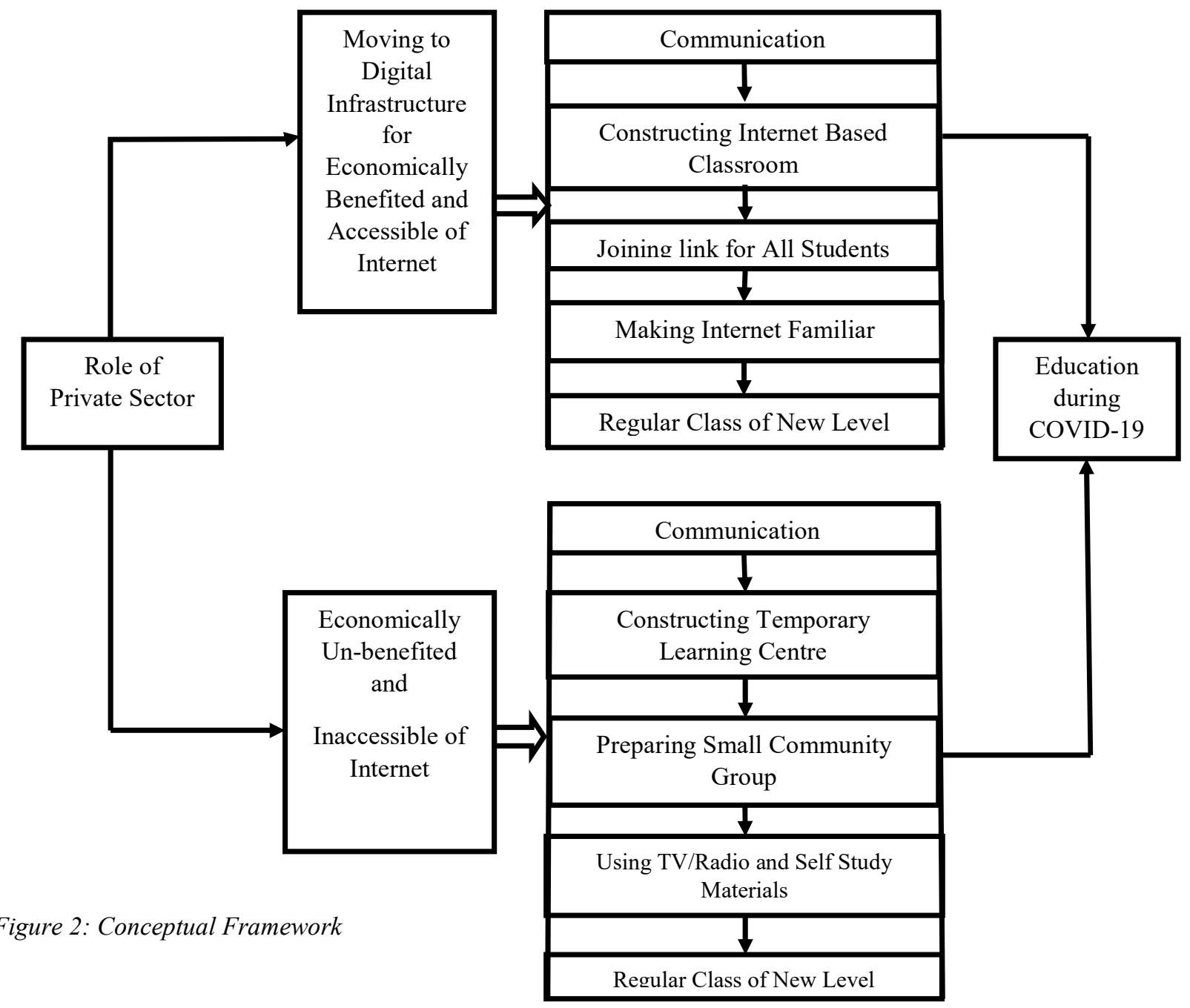

\section{DATA AND METHODS}

\subsection{Study Area}

A multistage sampling method was applied during the collection of data. Initially, Nepal was divided into seven provinces as seven clusters. Then a school was chosen from every province by simple random sampling method containing every ecological belt of Nepal. Also one school from Kathmandu valley was chosen since it contains the highest number of private schools in Nepal. The stratified random sampling method was used to select target respondents from both urban and rural areas private secondary schools of different provinces.

Respondents were divided into four different categories (SMC-1, Principal-, Teachers-1, Parents-1) belonged to secondary level private school. Vice chairman of Bagmati Province Planning Commission, some of head of education office and PABSON province chairman are the KII respondents of this study. 
Map of Study Area

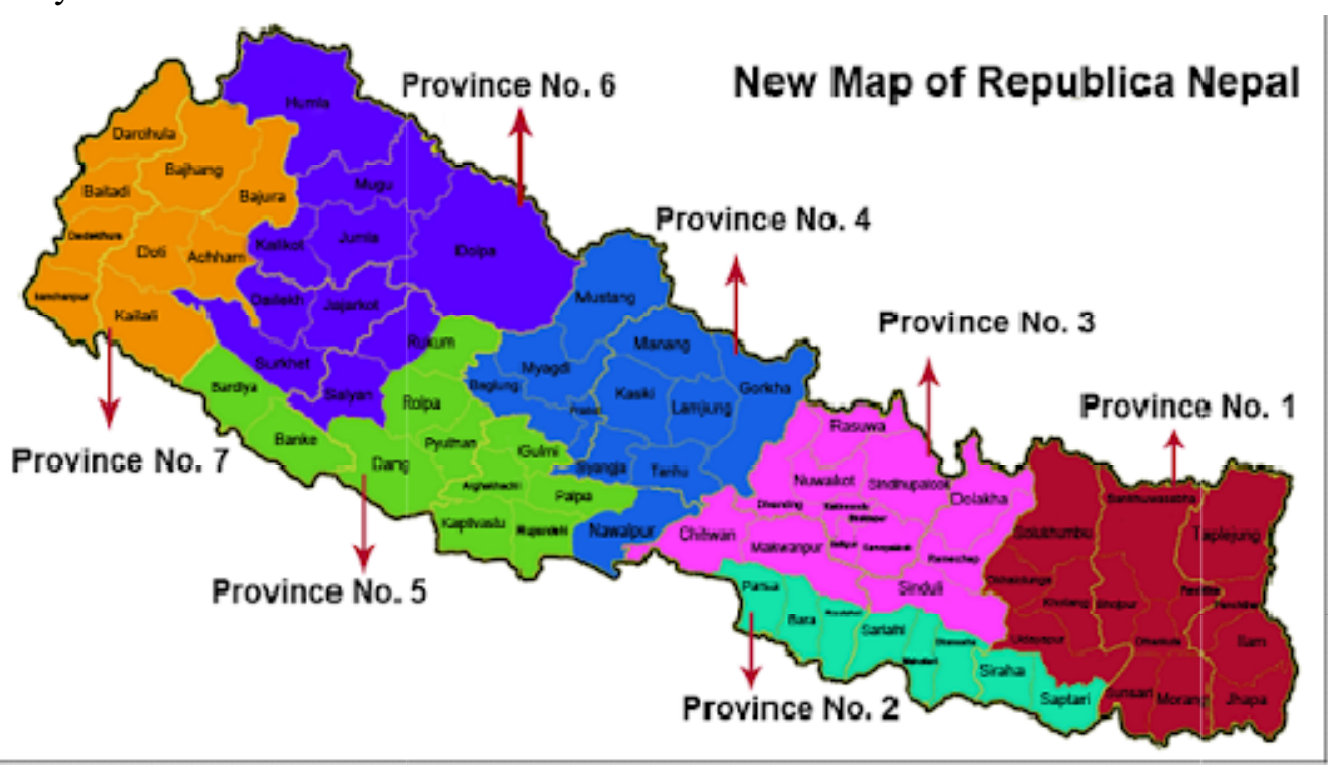

Figure 3: Map of Study Area

\section{Selection of Respondents and Pilot Study}

A total of 8 secondary private schools from 7 provinces was taken for the study. The data collection was done in year 2020 during the period of lockdown in the context of Covid -19. A total of 2 FGD was conducted and a standard questionnaire was used to collect the data. A pretest of each questionnaire was conducted in the month of May 2020 in 2 schools of Makwanpur and Kathmandu district and the results were verified through SPSS -Vol 20 statistical tools and this method highlighted the probability of the appropriate answer from the various respondents.

The period covers for data collection is on June 2020. Data collection was done through several visits to the related sites and from telecommunication with the above mentioned respondents as well as Vice chairman of the Bagmati Province Planning Commission, some of head of education office, PABSON province chairman, KII respondents and local community. Also the questionnaires were prepared in both Nepali and English language for the different respondents.

\section{Data Analysis Process}

SPSS Vol-20 statistical tools were used to interpret the quantitative aspects of the findings of this study. Also a descriptive analysis was more emphasized to elaborate the data with chi-square, cross tabulation and correlation analysis. Two FGD with different KII was conducted and the data were elaborated accordingly. 
International Research Journal of MMC (IRJMMC)

Vol. 2

Issue 1 (February, 2021)

ISSN 2717-4999 (Online)

2717-4980 (Print)

\section{RESULT AND DISCUSSION}

Table 10: Perception of Respondents on the Continuity of Education in the Period of COVID-19

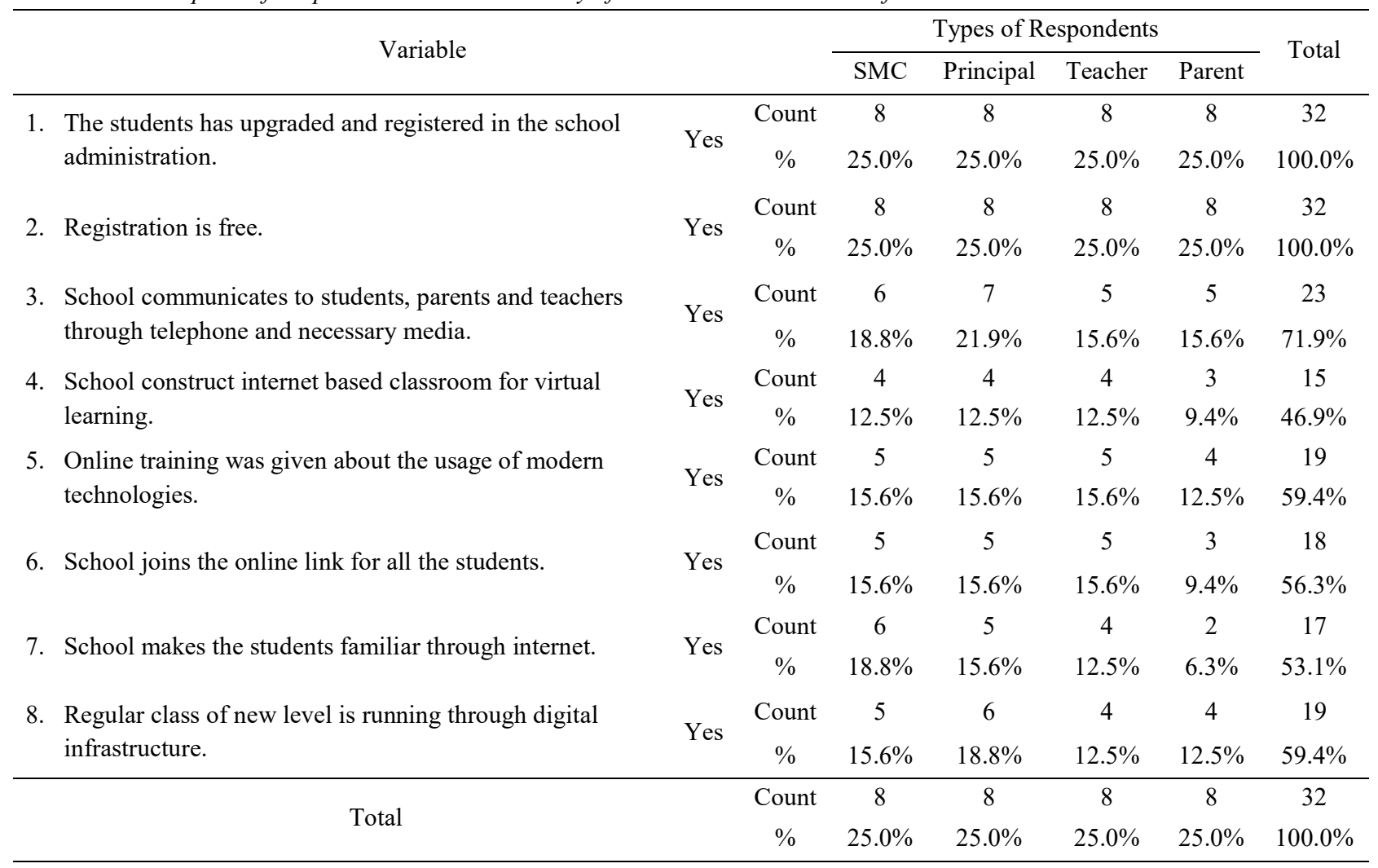

\section{Respondents' Positive Response \%}

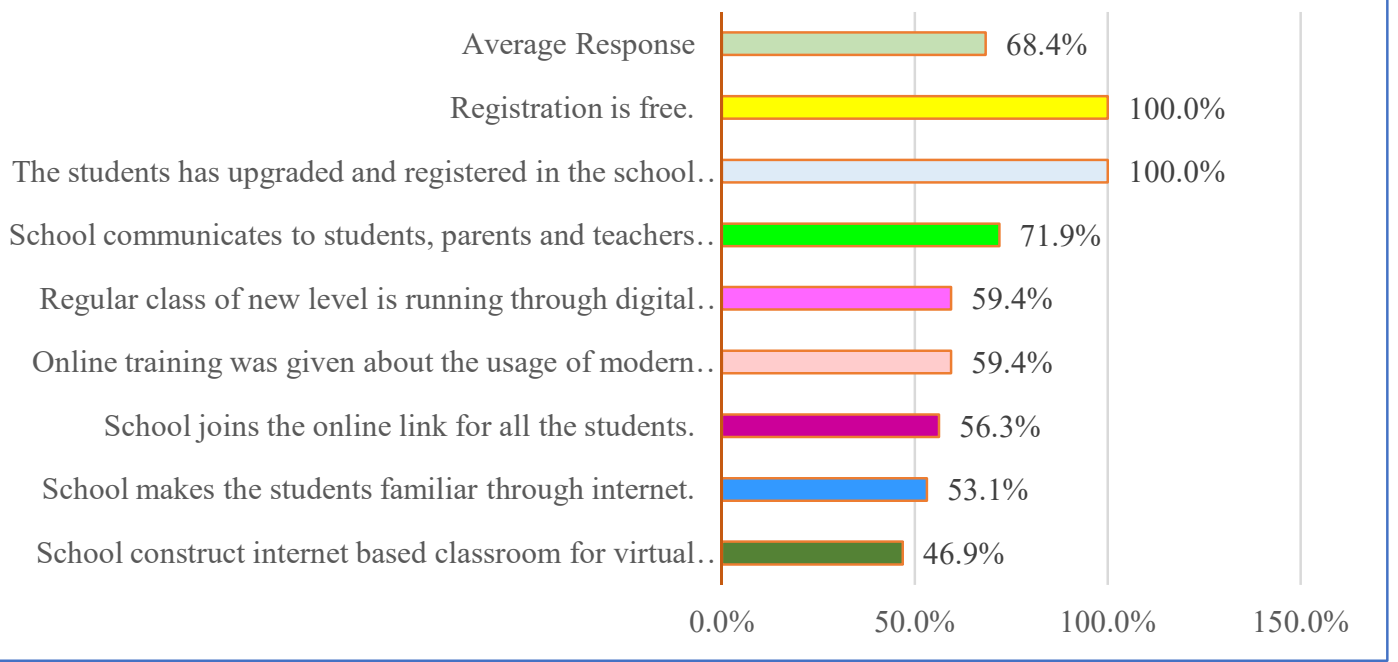

Figure 4: Perception of Respondents on the Continuity of Education in period of COVID-19

From the above table, all of the respondents are fully agreed on the fact that the students has upgraded and registered in the school administration as well as registration is free since there 
was not a favorable situation to open the account of school for financial purposes. But the majority of respondents disagree with the statement that school construct internet based classroom for virtual learning. Since in Nepal, most of the users connect Zoom cloud and Google meet apps and join in online classes from their own home. The above table also explains that more than $40 \%$ respondents don't agree with the statement that the school is giving online training, joining online links and making internet familiar. However, from the above questionnaire, there is a strong correlation between the view of principal and parents of continuing education and is 0.95 . Also, there is a strong relationship between the view of teacher with parents and students with parents and is 0.97 and 0.94 respectively.

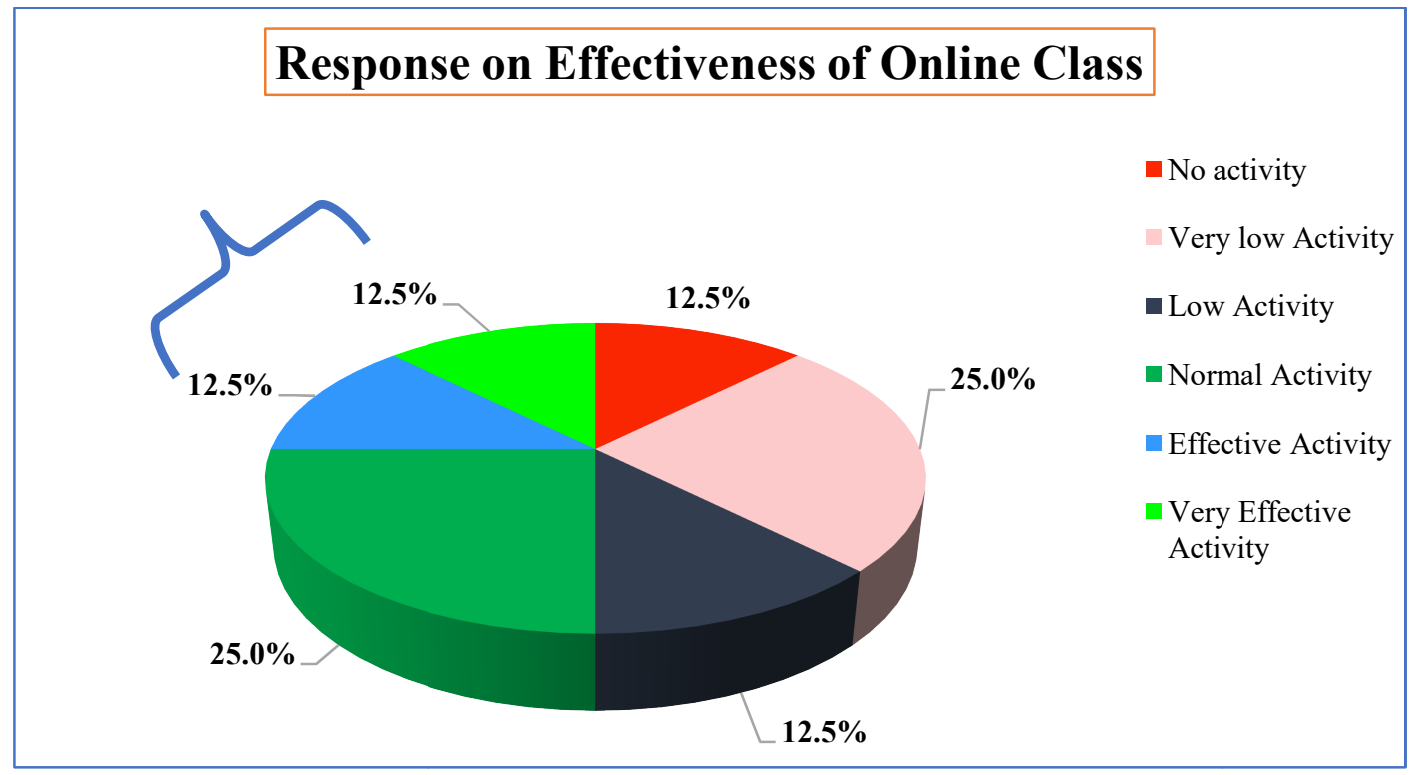

Figure 5: Response on Effectiveness of Online Class

Table 11:Chi-Square Test on Effective of Online-Class among the Respondents Perception Regarding Study Area

\begin{tabular}{lccr}
\hline & Chi-Square Tests & & \\
\hline Pearson Chi-Square & Value & df & Asymp. Sig. p (2-sided) \\
\hline
\end{tabular}

From the above table, the researcher concluded that there is no significant effect of online class continued by private sector as $\chi 2 \mathrm{c} 15 \mathrm{df}$ (Calculated value) $=13<\chi 2 \mathrm{t} 15 \mathrm{df}$ (Tabulated value) $=25$ at 0.05 level of significance. Also the value of $p=0.602>0.05$ shows that the effectiveness of online class continued by the private sector is highly insignificant and similar perception appears among the respondents during the study. So the null hypothesis is accepted in this research on the basis of the respondents of different parts of Nepal. The result also shows that the effectiveness of an online class is only $25 \%$ because of severe problems such as poor economic conditions, lack of different factors as electricity, internet and awareness and these problems should be solved by the government with the coordination of provincial and local government taking support of private sectors also. 
Through an FGD discussion and Key Informant Interview, some new facts were found that: A President of SMC of the private school of province number one expresses his view that: Private schools of urban area are running an online class smoothly in this pandemic period by communicating students, parents and teachers through telephone and other necessary media. Some schools construct internet based classroom for virtual learning and online training was given using modern technologies. So, regular class of new level is running through digital infrastructure. But there are still huge problems in rural areas. In a mountainous region, most of the people are facing electricity problem. Even they have not proper access of TV and radio and are trying to send their teachers in different common place and office of local organization.

In an FGD (Focus Group Discussion) on the school of province two, a principal has dissimilar perception as:

Initially the students were interested and joined online learning classes and but after a few weeks, many students were disappointed as they express that when the school will reopen, then the course will be reviewed by teachers. Also, some parents were totally negative in online education that the activities by which the private school are doing is just for collecting financial amount. Similarly, teachers told that 'following healthy rule with social distance' should be followed strictly. Also parent's focus on the unaffordability of internet adding the view that government should make the access of internet in remote areas with low price.

In an FGD of another school of Bagmati Province, a Principal gave his view that:

More than seventy-five percent students are attending on virtual classes regularly. Those who are not able to take virtual class, self study materials such as audio, video materials of classrooms were sent by different media as well as classes are shown on radio /TV also.

Most of the FGD discussions, including SMC, principal, teachers, parents and so many stakeholders of private school conclude that in an urban area which is economic strength, they are getting an online education without any disturbance. But the students of remote area as well as most of the public schools are not interested in doing any type of teaching learning activities showing the problem only.

A Vice Chairman of Bagmati Province Planning Commission expresses his view that:

Private school is playing a crucial role in continuing education in this critical period, even though they are not getting support from the government. As Bagmati Provincial Government are also supporting the orphans and disabled children per month Rs. 2 thousand to continue education, but the roles of public school were not found positive in this critical period and are not interested to continue education in some other possible ways. 
Regarding education, this province has different views:

On the same school, schools who are running English and Nepali medium both, English medium are running through online but Nepali medium instruction is not used properly, so the school administration should be serious to give equal chances for getting educational activities (Nepal, 2020).

A Chairman of District Education Coordination Committee of Gandaki Province said that: Most of the students of rural municipality left the online classes due to the lack of awareness, uninterested as well as expensive way to get knowledge. So government should 'redefine the distance education' in the context of urban and rural areas. Also the government should focus recent model of 'Kathmandu University Online Education Model' which seems to be effective and helps to bring the concrete online policy. Moreover, government should bring in depth plan based on the social relativity.

A resource person of education office of Province 5 said "some village municipalities are trying to continue education in this critical situation as Khajura, Baijanath and Narainapur Municipality are giving laptop for secondary school to get access of technology.

Another view by PABSON (Private \& Boarding Schools Organization) chairman of Karnali province explained that:

Due to the geographical barrier and lack of proper road access in mountain areas, sufficient electricity aren't provide because of the difficulty in supplying electricity-related materials. So online classes, T.V., radio as well as distance education are not appropriate. That's why the geographical area should be divided into different zone, such as red, green and yellow and after dividing, education should be continued by removing the quarantine from schools as soon as possible. Recently, there are no educational activities, but Pabson are planning to make a different small group of students in the community to continue education through the teachers on that place. Also "Temporary Learning Centre" should be created as soon as possible where the modern technologies are not available.

However, a resource person of Sudurpaschim Province has different problems and express that "we are facing huge electricity problems and micro hydro is open at night only which is not sufficient for them and is expecting sufficient electricity in rural areas near soon".

\section{CONCLUSIONS}

During a research study in the Covid -19 periods, following conclusions was drawn based on this study is here with: In urban area, private schools are running virtual classes using digital infrastructure. The majority of stakeholders of private school are feeling positive towards the effectiveness of online classes. In remote areas, due to lack of electricity and poverty, private school are not able to continue education. Most of the private schools in village area are trying to continue education by making small groups in the community. Some reputed community schools 
are trying to follow the model of private school about using modern technology for virtual learning.

\section{RECOMMENDATIONS}

- Government should provide electricity and internet facility in remote as well as in socially deprived areas and private school should continue education through e-learning, TV/radio and other media.

- Government as well as private sector, both should prepare 'Temporary Learning Centre' (TLC) in the marginalized community of learners.

- Most of the public and so many private schools are not conducting teaching learning activities during COVID-19 period, so the government should bring and apply 'Learning Continuity Plan' (LCP) strictly to continue the education.

\section{ACKNOWLEDGEMENTS}

Since this study is not possible without the support of respondents and my entire research team members, I am very much thankful to all the respondents during the study. For this article, I would like to pay my deepest gratitude to my respected supervisor Prof. Dr Siddhi Prasad Koirala, who guided and supported me for finalizing this article. Special thanks to Dr. Bijaya Nepal and Raju Chhetry of Mewar University for their continuous support to make this article in this form. I am also thankful to my college Deepak Gautam who supported me for collecting data in this study. I am also thankful to Vice Chairman of Bagmati Province Planning Commission Shyam Basnet, members of FGD, other KII and many other stakeholders who directly /indirectly supported me in my research study.

\section{REFERENCES}

Chauhan, S. (2020, June 1). Comprehensive review of Coronavirus disease 2019 (COVID-19). Biomedical Journal, 1-8. doi:10.1016/j.bj.2020.05.023

Crawford, J., Butler-Henderson, K., Rudolph, J., Malkawi, B., Glowatz, M., Burton, R., .. . Lam, S. (2020). COVID-19: 20 countries' higher education intra-period digital pedagogy responses. Journal of Applied Learning \& Teaching, 3, 1-20.

Giorgi, B. D. (2020, April). Transition to online education in schools during a SARS-CoV-2 Coronavirus (COVID-19) pandemic in Georgia. 5(4), 1-9. doi:10.29333/pr/7937

James Francis Miradora, M. K. (2020). Ensuring education continuity in the time of COVID-19. The Asia Foundation.

Jingjing, L. (2015). Analysis of family education/school education and personal development. European Journal of Research in Social Sciences, 3(1), 1-11.

Lindsay, 1., \& Whalley, R. (2020). Building resilience in New Zealand schools through online learning. Association for the Advancement of Computing in Education, 55-58. Retrieved from http://aace.org 
Mandal, G., \& Goswami, T. K. (2016). Privatization of school education in the Midnapore district of West Bengal. International Journal of Latest Technology in Engineering \& Management, 2(1), 7-10.

Murati, R. (2016). School as education indicator. Journal of Education and Practice, 7(3), 69-71.

Nepal, D. B. (2020, 6 10). Biasness on education. (D. C. Manandhar, Interviewer)

Norden, B. (2012). Sustainable development through global learning and teaching. Researchgate, 3-26.

Qun Li, M. X. (2020, March 26). Early transmission dynamics in Wuhan, China of Novel Coronavirus-infected pneumonia. The New England Journal of Medicine, 382(13), 11991207. doi:10.1056/NEJMoa2001316

Reimers, F., Schleicher, A., Saavedra, J., \& Tuominen, S. (2020). Supporting the continuation of teaching and learning during the COVID-19 Pandemic. Global Education Innovation Initiative.

Shrikrushna Subhash Unhale*, Q. B., Sanap, S., Thakhre, S., Wadatkar, S., Bairagi, R., Sagrule, P. S., \& Biyani, P. D. (2020). A review on Corona virus (Covid-19). World Journal of Pharmaceutical and Life Sciences, 6(4), 109-115.

Singhal, T. (2020, March). A Review of Coronavirus disease-2019 (COVID-19). The Indian Journal of Pediatrics, 1-7.

Verger, A., Clara, F., \& Adrian, Z. (2016). The Privatization of education: A political economy of global education reform. Newyork and London: Teachers College Press. Retrieved from https://lccn.loc.gov 